\title{
Innovative Approaches to Address Social Determinants of Health Among Adolescents and Young Adults
}

\author{
Kathleen P. Tebb, ${ }^{1, *}$ Gingi Pica, Lauren Twietmeyer, Angela Diaz, and Claire D. Brindis ${ }^{1,4}$
}

\begin{abstract}
Background: Social determinants are the leading causes of health disparities. Yet health care systems have not systemically addressed social determinants of health as it pertains to adolescents and young adults (AYAs), among other populations in need. This study identified promising innovative programs across the United States. Methods: Thirteen representatives from 10 programs completed a 45-min telephone interview. Transcripts were reviewed and analyzed to identify cross-cutting themes.

Results: Strategies included increasing access to quality, comprehensive and confidential health services, addressing the holistic needs of AYAs, collaborations across the health care delivery systems and other community services, and leveraging technology.
\end{abstract}

Conclusion: This study showcased innovative approaches to inform future efforts.

Keywords: social determinants of health; interventions; adolescents; young adults

\section{Background}

Disparities in health outcomes are a result of a myriad of socioecological factors that are linked to education, employment, income, discrimination based on race/ ethnicity, gender, religion, sexual orientation, geographic location, mental health, and/or disability. These factors are commonly referred to as social determinants of health (SDOH).Worldwide, SDOH (e.g., structural factors such as national wealth, income inequality, and access to education) have the strongest impacts on adolescent health. ${ }^{1}$

In the health care system, providers traditionally respond to the presenting health issue, rather than working upstream to address the underlying factors (SDOH). Although most adolescents and young adult (AYA) health morbidity and mortality are largely preventable, providers face challenges in engaging with other systems that influence young people, such as schools, juvenile justice, and social service systems, to respond to the myriad needs of young people. The purpose of this study was to identify programs, across the United States, where the health care delivery system and the broader community are working together to address the root causes of health disparities $(\mathrm{SDOH})$ and promote health equity for AYAs.

Despite been recent attention to $\mathrm{SDOH}$, the concept is not new. In the United States, the concept of SDOH emerged in the early 1900s, but did not have a major influence on public policies until the 1950s. ${ }^{1}$ The first documented major disparities in health outcomes were not published until $1985^{2}$ and though this spurred additional initiatives, ${ }^{3-5}$ progress remained slow. In 2003, the Institute of Medicine reported disparities in health care access and quality among racial and ethnic

\footnotetext{
${ }^{1}$ Division of Adolescent and Young Adult Medicine, Department of Pediatrics, Benioff Children's Hospital and the Adolescent and Young Adult Health National Resource Center, University of California, San Francisco, California.

${ }^{2}$ ICF International, New York, New York.

${ }^{3}$ Icahn School of Medicine at Mount Sinai and Mount Sinai Adolescent Health Center, New York, New York.

${ }^{4}$ Philip R. Lee Institute for Health Policy Studies and the Adolescent and Young Adult Health National Resource Center, University of California, San Francisco, California.

*Address correspondence to: Kathleen P. Tebb, PhD, Division of Adolescent and Young Adult Medicine, Department of Pediatrics, Benioff Children's Hospital, University of California, Box 0503, LH245, San Francisco, CA 94143, E-mail: kathleen.tebb@ucsf.edu
}

(c) Kathleen P. Tebb et al. 2018; Published by Mary Ann Liebert, Inc. This Open Access article is distributed under the terms of the Creative Commons License (http://creativecommons.org/licenses/by/4.0), which permits unrestricted use, distribution, and reproduction in any medium, provided the original work is properly cited. 
minorities, ${ }^{3}$ and more recently, there has been greater attention to health disparities among AYAs, including non-whites, immigrants, lesbian, gay, bisexual, transgender, queer/questioning (LGBTQ), foster care, juvenile justice, homeless, and youth from underserved geographical areas. ${ }^{6}$ These populations are at a greater risk for poor health outcomes (e.g., injury, substance use, obesity, poor mental, sexual, oral, and other health problems) ${ }^{7-13}$ $\mathrm{SDOH}$ also contribute to health care access and utilization, which further impacts health outcomes.

While social determinants have been documented as contributing to negative outcomes, multisectoral approaches to implementing interventions aimed at eliminating or ameliorating the impact of social determinants is nascent, particularly in terms of partnerships with health care providers (who often are at the forefront of encountering the impact of poor living environments, food intake, trauma, etc.). The purpose of this study is to identify programs across the United States, working to address SDOH and identify strategies to inform how the health care system and the broader community can better work together in addressing $\mathrm{SDOH}$ and promote health equity.

\section{Methods}

Programs were identified through a literature and Internet search using the terms "adolescent," "young adult," "teen," "social determinants of health," "health equity," and "preventive care." We also sought programs from known initiatives aimed at addressing SDOH: CDC's Racial and Ethnic Approaches to Community Health, National Prevention and Health Promotion Strategy, National Partnership for Action to End Health Disparities, Maternal and Child Health Bureau, ${ }^{14-17}$ and the Robert Wood Johnson Foundation. ${ }^{18}$ Fifteen programs were identified. We reached out to all 15 programs; 4 programs were no longer operating and 1 did not respond after four attempts. Programs came from a range of regions across the United States (California, Colorado, Massachusetts, New Mexico, New York, Rhode Island, and South Carolina). Table 1 provides a brief description of each program. We initially reached out to direct program leaders to interviews, and were referred to additional project staff to provide a more complete perspective on the program and/or topic. Thirteen individuals across 10 programs agreed to participate in 45-min semistructured telephone interviews that asked about their program, efforts to address $\mathrm{SDOH}$, and challenges (Table 2). Interviews were recorded, transcribed, and analyzed to identify key themes. Transcripts were independently coded by two researchers and discrepancies were resolved through discussion. All participants provided consent to use their quotes and were allowed to review and approve them before publication. The University of California, San Francisco's IRB approved this study.

\section{Results}

The primary focus of the interviews were to identify strategies in which health organizations worked in tandem with other types of community agencies to better respond to the myriad needs of their patients that went far beyond "clinic walls" to address SDOH. Participants were also asked to comment on challenges encountered. These findings are summarized hereunder. Table 3 provides quotes that further illustrate these themes.

All interviewees stated that it was critical to form community partnerships across multiple sectors to address $\mathrm{SDOH}$. Most individuals need services that span different programs, for example, health, education, juvenile justice, and social services. Benefits of these partnerships include raising awareness of community programs, increasing AYAs' access to services, identifying gaps, and building support for and capacity to meet the needs of AYAs ("3.1" in Table 3).

\section{Addressing poverty, a key SDOH}

Interviewees universally acknowledged poverty as an important SDOH. Programs implemented a number of different strategies to address this SDOH. The most common approach involved educational supports, job training, and career pathways. For instance, the Door's embeds health care services for AYAs within a larger positive youth development program that offers comprehensive career and education programs and opportunities to develop job and life skills. In addition, the Mount Sinai Adolescent Health Center (MSAHC) provides comprehensive integrated health services, leadership training, education and skill development, and legal and social services to help AYAs overcome challenging circumstances such as the ability to return to or stay in school, and find sustained employment ("3.2" in Table 3). Similarly, the The Los Angeles Trust for Children's Health (L.A. Trust) supports comprehensive access to health and wellness and also provides AYAs from low-income, high-risk neighborhoods with skill development, and employment opportunities in health care through employer, community, and state college partnerships. 
Table 1. Overview of Intervention Approaches by Region in the United States

\begin{tabular}{|c|c|c|c|}
\hline Program & Funding & Brief description & AYA populations served \\
\hline $\begin{array}{l}\text { The Los Angeles Trust } \\
\text { for Children's Health, } \\
\text { Los Angeles, CA }\end{array}$ & $\begin{array}{l}\text { CA-based Community } \\
\text { Foundation \& Endowment; } \\
\text { CVS Caremark; Kaiser } \\
\text { Permanente S. CA }\end{array}$ & $\begin{array}{l}\text { Improve student achievement by increasing } \\
\text { access to integrated health care and preventive } \\
\text { services at } 14 \text { Wellness Centers }\end{array}$ & $\begin{array}{l}\text { Adolescents at SBHCs, younger } \\
\text { students and their } \\
\text { families }\end{array}$ \\
\hline $\begin{array}{l}\text { One Degree, San } \\
\text { Francisco, CA }\end{array}$ & $\begin{array}{l}\text { Technology entrepreneurs, } \\
\text { foundations, and government }\end{array}$ & $\begin{array}{l}\text { A technology-driven organization linking low- } \\
\text { income people with community resources }\end{array}$ & $\begin{array}{l}\text { Low-income individuals, } \\
\text { including AYAs and families }\end{array}$ \\
\hline $\begin{array}{l}\text { SHCIP, New Mexico } \\
\text { and Colorado }\end{array}$ & $\begin{array}{l}\text { Centers for Medicare and } \\
\text { Medicaid }\end{array}$ & $\begin{array}{l}\text { Identifies effective replicable strategies for } \\
\text { enhancing health care quality through } 22 \mathrm{SBHCs}\end{array}$ & $\begin{array}{l}\text { School-age children } \\
\text { and adolescents }\end{array}$ \\
\hline The Door, New York, NY & $\begin{array}{l}\text { Public/private; Title X federal } \\
\text { funds; City \& State } \\
\text { Department of Health }\end{array}$ & $\begin{array}{l}\text { Comprehensive health and development services } \\
\text { to AYAs, including reproductive health, mental } \\
\text { health, legal assistance, educational support, } \\
\text { college preparation, and English tutoring }\end{array}$ & Youth ages $12-24$ years \\
\hline Housing $\mathrm{Rx}$, Boston, $\mathrm{MA}$ & $\begin{array}{l}\text { Boston Foundation's Health } \\
\text { Starts at Home Initiative }\end{array}$ & $\begin{array}{l}\text { Reduce housing instability among low-income } \\
\text { families with young children }\end{array}$ & $\begin{array}{l}\text { Low-income families with } \\
\text { children }\end{array}$ \\
\hline $\begin{array}{l}\text { Progreso Latino, } \\
\text { Rhode Island }\end{array}$ & $\begin{array}{l}\text { CDC, grant funding, and } \\
\text { fee-for-service }\end{array}$ & $\begin{array}{l}\text { Connects Latinos and immigrants to free health } \\
\text { care, dual-language adult education, and free/ } \\
\text { low-cost immigration legal services }\end{array}$ & $\begin{array}{l}\text { Underserved and uninsured } \\
\text { Latino and immigrant } \\
\text { populations, including AYAs }\end{array}$ \\
\hline $\begin{array}{l}\text { Mount Sinai Adolescent } \\
\text { Health Center, } \\
\text { New York, NY }\end{array}$ & $\begin{array}{l}\text { Government grants, } \\
\text { foundations, clinic } \\
\text { reimbursement, other } \\
\text { gifts/donations }\end{array}$ & $\begin{array}{l}\text { Delivers high-quality, comprehensive, confidential, } \\
\text { and free health care. Outreach also provided } \\
\text { through } 24 \text { middle- and high-school SBHCs }\end{array}$ & $\begin{array}{l}\text { AYAs } 10-24 \text { yrs; low-income, } \\
\text { uninsured, teen parents, and } \\
\text { their children, immigrants, } \\
\text { refuges, LGBTQ, transgender, } \\
\text { homeless, and sex trafficked } \\
\text { youth }\end{array}$ \\
\hline $\begin{array}{l}\text { New York City Teen } \\
\text { Center, New York, NY }\end{array}$ & $\begin{array}{l}\text { U.S. Department of Health and } \\
\text { Human Services' Office of } \\
\text { Adolescent Health; city tax } \\
\text { levies }\end{array}$ & $\begin{array}{l}\text { Connects youth with } \mathrm{CBO} \text {, schools, and clinics to } \\
\text { promote evidence-based teen pregnancy } \\
\text { prevention programs and access to sexual } \\
\text { health care across three geographic } \\
\text { communities in NYC }\end{array}$ & 15,000 youth ages $15-19$ years \\
\hline $\begin{array}{l}\text { Bronx Health REACH, } \\
\text { Bronx, NY }\end{array}$ & $\begin{array}{l}\text { CDC, National Center on Minority } \\
\text { Health and Health Disparities, } \\
\text { Johnson and Johnson, Johns } \\
\text { Hopkins Community } \\
\text { Healthcare Scholars }\end{array}$ & $\begin{array}{l}\text { Reduce racial/ethnic disparities through health } \\
\text { education and outreach, policy and system } \\
\text { changes through evidence-based and } \\
\text { community-informed interventions }\end{array}$ & $\begin{array}{l}\text { Serves low-income youth and } \\
\text { immigrant youth; almost all } \\
\text { are Hispanic or African } \\
\text { American }\end{array}$ \\
\hline $\begin{array}{l}\text { Spartanburg County } \\
\text { Community Indicators } \\
\text { Project South Carolina, } \\
\text { Spartanburg, SC }\end{array}$ & $\begin{array}{l}\text { CDC, Robert Wood Johnson } \\
\text { Foundation, and Duke } \\
\text { Endowment }\end{array}$ & $\begin{array}{l}\text { Collect data on health indicators, set improvement } \\
\text { goals, and work with CBOs to coordinate } \\
\text { improvements }\end{array}$ & $\begin{array}{l}\text { Residents of Spartanburg, South } \\
\text { Carolina including children } \\
\text { and AYAs }\end{array}$ \\
\hline
\end{tabular}

AYA, adolescents and young adult; LGBTQ, lesbian, gay, bisexual, transgender, queer/questioning; MSAHC, Mount Sinai Adolescent Health Center; NYCTC, New York City Teen Center; SCIP, Spartanburg Community Indicators Projects; SHCIP, School-Based Health Center Improvement Project.

Prior research shows that poverty is linked with housing instability that, in turn, places youth and their families at risk of adverse health outcomes. ${ }^{19}$ Boston Medical Center launched Housing Prescriptions $(\mathrm{Rx})$ to mitigate adverse health outcomes that stem from housing instability. In this approach, the medical setting identifies at-risk families and provides them with a housing $\mathrm{Rx}$ that is used to link participants with a communitybased case manager that provides specialized housing support, linkages to resources, and fast-tracks eligible families into public housing units ("3.3" in Table 3).

Poverty is also a predictive factor in teen pregnancy rates, which, in turn, increases the risk of poverty and poor health outcomes of the teen parent(s) and their offspring. A couple of programs focused on addressing this $\mathrm{SDOH}$ through teen pregnancy prevention efforts that include evidence-based, comprehensive and confidential, sexual health education and services. For example, the Spartanburg Community Indicators Projects (SCIP) worked with Medicaid to change state-level policies to allow intrauterine device placement at delivery and post-partum visits to reduce repeat teen pregnancies ("3.4" in Table 3). In another example, the L.A. Trust partnered with researchers to develop and evaluate a mobile health application to provide patient-centered evidence-based comprehensive contraceptive information and access to reduce disparities in unintended pregnancies among Latina adolescents. ${ }^{20}$ Other programs such as the Door and MSACH also incorporate teen pregnancy prevention efforts that are multifaceted and include educational, medical, and social/economic approaches. 
Table 2. Questions for Semistructured Interviews

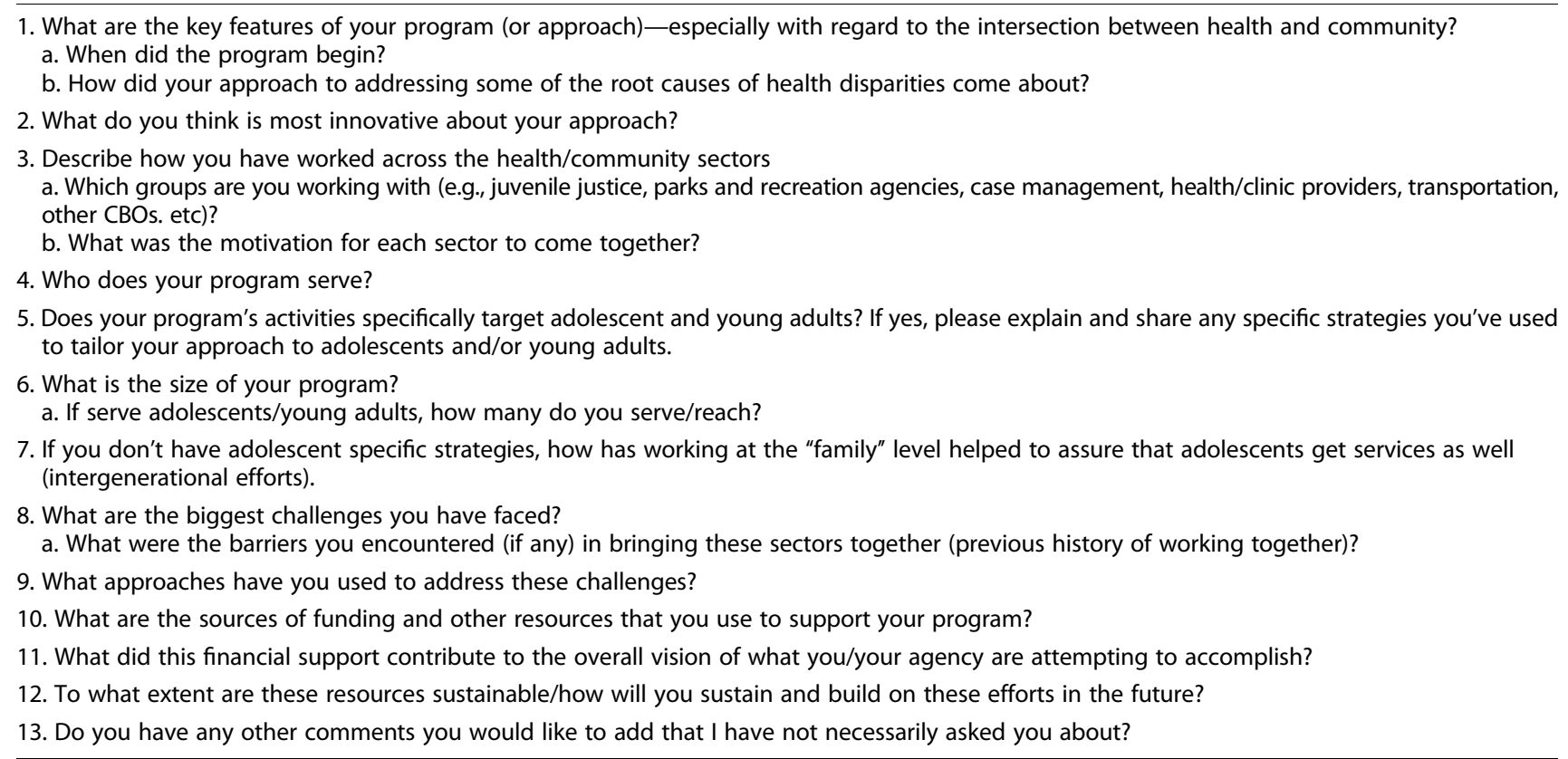

In yet another approach, One Degree, a nonprofit technology-driven organization, strives to "empower people to create a path out of poverty for themselves and their communities." Through their web and mobile platform (1degree.com), low-income individuals and families can get linked with community resources (e.g., housing, health care, and food banks). This tool has been integrated in a number of health clinics to address food insecurities and other needs associated with poverty. A growing number of pediatric providers are screening families for food insecurities as part of the American Academy of Pediatrics efforts to address this SDOH. ${ }^{21}$ When a family is identified as experiencing food insecurities, the One Degree application (app) can be used to link families to local resources (complete with walking directions and public transportation routes).

\section{Providing holistic and comprehensive health}

care with linkages to other services

Many programs identified unequal access to quality health care services as a major SDOH and focused efforts on promoting equity in AYAs' access to health care and improving health care quality for all AYAs. In particular, MSAHC serves AYAs regardless of their ability to pay or their insurance status and provides holistic, confidential, comprehensive, integrated medical, sexual and reproductive health, dental, optical, behavioral and mental health, prevention, and support services. The Door also provides a wide range of services, in one location, that are free and confidential, including reproductive health care and education, mental health counseling and crisis assistance, legal assistance, academic support, job training and placement, supportive housing, recreational and arts activities, and nutritious meals. The New York City Teen Center (NYCTC) brought together youth, community-based organizations, schools, citywide agencies, and $>66$ teen-friendly clinics to ensure that every teen has access to high-quality comprehensive health services. The L.A. Trust supports a network of Wellness Centers that serves students in Los Angeles and provides comprehensive care, including oral health, asthma, reproductive health, substance abuse prevention, and mental health services ("3.3.a." in Table 3). They also utilize promotoras ${ }^{\star}$ who engage with families to support communication about healthy relationships and behaviors.

A few programs also utilize data-driven approaches to identify needs, monitor progress, and inform continuous quality improvement efforts. For example, the School-Based Health Center Improvement Project (SHCIP) enhancing the quality of health care for youth with a special focus on increasing access for adolescents, with the lowest rates of primary care use. They implemented an electronic Student Health

*Promotoras are Hispanic/Latina women in the community who are trained to provide health information to other members of their community. 


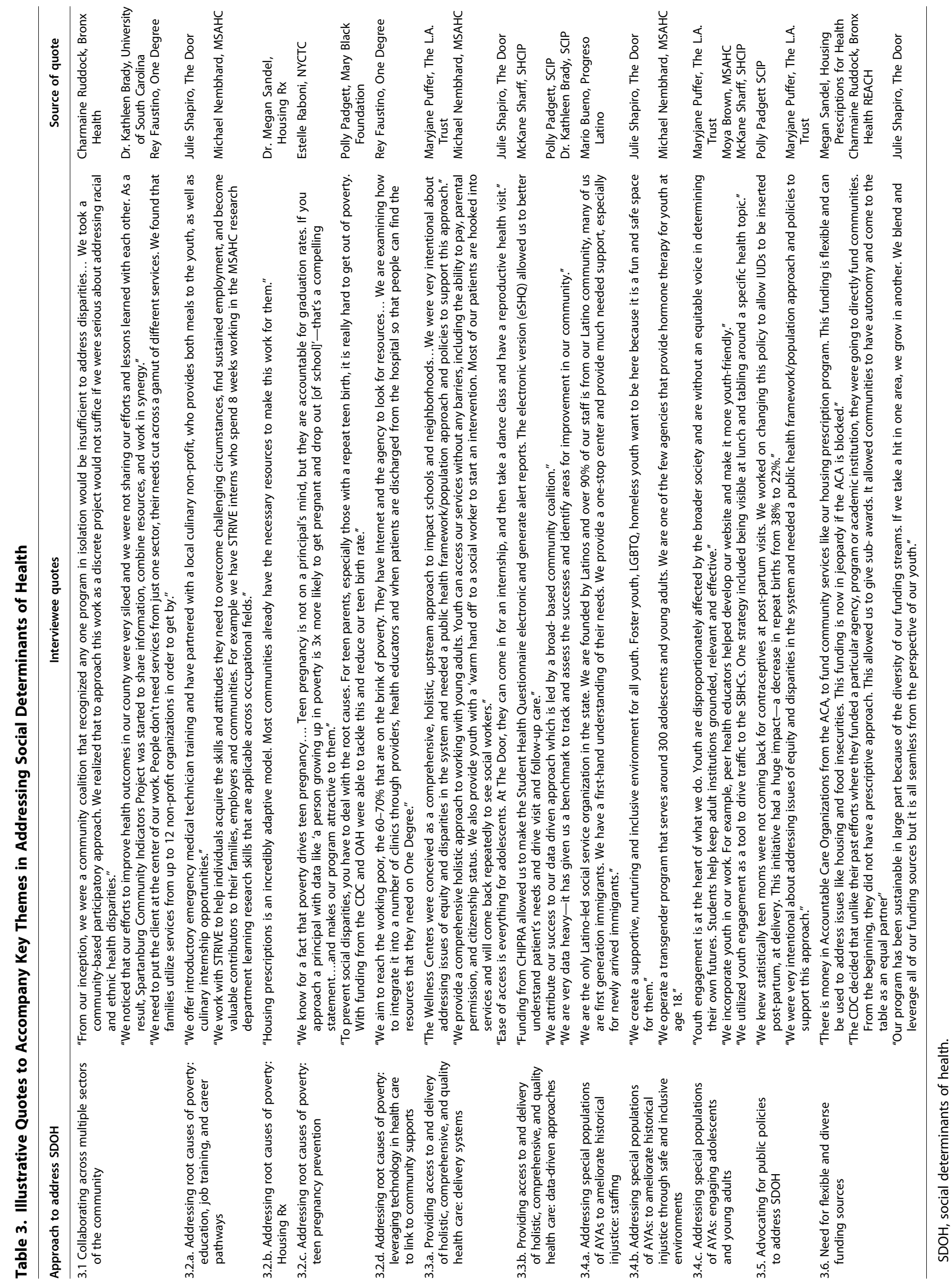


Questionnaire to assess for risk and protective factors through an iPad at the medical appointment. Providers could view the results immediately and use them to guide the visit. This approach ensures all youth receive comprehensive screening and appropriate care. MSAHC also uses technology to promote quality of care through Health Squad that encourages AYAs to ask questions and request support 24/7 for a response within one business day. It also provides AYAs with medication reminders and health information. Using data-driven quality improvement approaches, for example, SCIP collects county-level population data on health outcomes and trends to collectively decide on focus areas, set improvement goals, coordinate improvement efforts, and track and report on progress (“3.3.b," in Table 3).

In addition, there was wide-spread recognition that special populations of AYAs needed targeted approaches to ensure access as long-standing discrimination based on race/ethnicity, gender, religion, sexual orientation, geographic location, mental health, disability, age, income, etc that has limited health care access. Approaches to mitigate this $\mathrm{SDOH}$ include hiring staff who reflect the background of the populations they serve ("3.4.a." in Table 3) and creating safe/welcoming environments for all AYAs (“3.4.b." in Table 3). Engaging youth was central to several programs to ensure youth-centered and inclusive programming. For example, MSAHC utilized peer educators to develop their teen-friendly website, and the L.A. Trust engaged youth advisors to inform the organization and board of directors about students' perceptions of the Wellness Centers to improve student utilization (“3.4.c." in Table 3).

\section{Advocating for broader public policies to address $\mathrm{SDOH}$}

Interviewees revealed that policy changes are a critical component to promoting social justice and health equity. For example, Bronx Health REACH created policies to address $\mathrm{SDOH}$ at the local and state level. ${ }^{22}$ They instituted school-based initiatives, including a policy to replace whole milk in all 1579 public schools and legislation requiring students to receive statemandated physical education. ${ }^{23}$ They launched \#Not62 campaign for a healthy Bronx, which incorporates a community call to action for elected officials, faith-based leaders, health care executives, and community members to create the infrastructure needed to address social and economic factors to promote health equity ${ }^{24}$ (“ 3.5 " in Table 3 ).

\section{Challenges}

The most significant challenge all interviewees faced was a lack of stable funding to sustain intervention efforts. Funding was often short term and/or targeted. Several interviewees from organizations, including the Door, Progresso Latino, the L.A. Trust, NYCTC, MSAHC, and Bronx Health REACH, stated that diverse funding was critical to their sustainability as it enabled them to withstand cuts to any one particular funding source. In addition, Housing Rx utilizes community partners, representing different funding streams, to maximize the benefits an individual may be eligible to receive (" 3.6 " in Table 3). However, this approach created challenges in managing different funders' requirements that targeted different problem areas or populations with different eligibility criteria, different reporting requirements, etc. It also makes it more difficult to provide seamless services. Others mentioned challenges with infrastructure and capacity to meet the needs of AYAs, especially in underresourced settings. A few commented on challenges integrating new technologies citing a number of issues including staff training, availability of IT support for wireless connections, and application updates. Some also mentioned that it can be overwhelming for community agencies and providers to respond to $\mathrm{SDOH}$ as there are many complexities to any given SDOH. A couple of participants also noted a lack of political will for broader solutions to address root causes of health disparities.

\section{Conclusion}

Addressing SDOH for AYAs is complex, yet this study provides examples of existing efforts across the United States that can offer some guidance for future endeavors. All of the programs featured in this study created linkages between the health sector with other influential community stakeholders to improve coordination across multiple sectors of health, social, and community-based programs and services. This coordinated approach was evident across each of the strategies aimed at addressing $\mathrm{SDOH}$. For instance, in tackling poverty, the health and social service sectors worked together in implementing a range of approaches (job/skill preparation, housing prescriptions, and teen pregnancy prevention effort). Inequalities in access to health care and quality of health services were another major $\mathrm{SDOH}$ many programs tackled through providing holistic comprehensive care that was data driven, safe, inclusive, and engaged AYAs to ensure programming is relevant and effective at meeting their unique needs. In addition, a few 
programs also targeted the "upstream" social-ecological factors through advocating for broader policies to address root causes of poverty, unstable housing, food insecurity, and other factors.

Innovative and stable financing strategies are needed to address $\mathrm{SDOH}$, outside of the hospital/clinic setting, to promote access to healthy foods, housing, transportation, employment, etc. as the links between these factors and health outcomes are well established. There is also a need for more comprehensive and well-evaluated approaches to tackle these complex and difficult challenges, including the root causes of discrimination and poverty. A social disparity and an equity lens need to underlie the strategies adopted by a wide array of health and nonhealth providers, programs and institutions that interact directly and indirectly with AYAs and their families.

\section{Acknowledgments}

We are grateful to Atlantic Philanthropies for its support of this research. This study is part of a larger study commissioned by the leadership of Mount Sinai Adolescent Health Center (MSAHC) to explore how federal and state policy issues affect service delivery and the financing of care for young people. ICF was selected to conduct the independent evaluation of the MSAHC, and ICF partnered with the Philip R. Lee Institute for Health Policy Studies, the Department of Pediatrics, Division of Adolescent and Young Adult Medicine, and the UCSF Benioff Children's Hospital at the University of California, San Francisco, to conduct this social disparities policy study. The development of this brief was also partially supported by grant No. U45MC27709 from the Department of Health and Human Services, Health Resources and Services Administration, Maternal and Child Health Bureau (Title V, Social Security Act), Division of Child, Adolescent and Family Health, and Adolescent Health Branch (Adolescent and Young Adult Health National Resource Center: http://nahic.ucsf.edu/resource-center/).

The authors thank the study participants for their time and their sharing of their valuable insights (listed alphabetically by last name).

- Kathleen Brady, PhD, MEd, Vice Chancellor of Planning, Institutional Research and Metropolitan Studies, University of South Carolina Upstate, SCIP.

- Moya Brown, MPH, Coordinator of Health Education and Peer Educators, Mount Sinai Adolescent Health Center.
- Mario Bueno, MEd, Executive Director, Progreso Latino.

- Rey Faustino, MPP, Founder, One Degree.

- Renee McConey, MS, Director of the Adolescent Health Center, The Door.

- Michael Nembhard, LCSW, Coordinator of Mental Health Services, Mount Sinai Adolescent Health Center.

- Polly Padgett, Adolescent Health Project Director, Mary Black Foundation, SCIP.

- MaryJane Puffer, MPA, Executive Director, LA Trust for Children's Health.

- Estelle Raboni, MPH, MCHES, Director, NYCTC.

- Charmaine Ruddock, MS, Project Director, Bronx Health REACH.

- Megan Sandel, MD, MPH, Principal Investigator of Housing Prescriptions as Health Care, Boston Medical Center.

- Julie Shapiro, MPP, Executive Director, The Door.

- McKane Sharff, MS, previously the Program Manager for the School-Based Health Center Quality Improvement Initiative, Envision New Mexico, SHCIP.

We would also thank Ken Peake, DSW, Anne Nucci, $\mathrm{MD}$, and Anthony Salandy, PhD, MS, from the MSAHC for their support. The views expressed in the interviews and presented in this report are those of the individual participants and do not necessarily reflect those of their affiliated institutions.

\section{Author Disclosure Statement}

No competing financial interests exist.

\section{References}

1. Thomas S, Quinn S, Butler J, et al. Toward a fourth generation of disparities research to achieve health equity. Annu Rev Public Health. 2011;32:399-416.

2. Hecker M. Report of the Secretary's Task Force on Black and Minority Health. U.S. Department of Health and Human Services. Published October 16, 1985. Available at https://collections.nlm.nih.gov/catalog/ nlm:nlmuid-8602912-mvset Accessed February 25, 2017.

3. Institute of Medicine. Unequal Treatment: Confronting Racial and Ethnic Disparities in Healthcare. Washington, DC: The National Academies Press, 2003.

4. Institute of Medicine. How Far Have We Come in Reducing Health Disparities? Progress Since 2000-Workshop Summary. Washington, DC: The National Academies Press, 2012.

5. U.S. Department of Health and Human Services, Office of the Secretary, Office of the Assistant Secretary for Planning and Evaluation and Office of Minority Health. HHS Action Plan to Reduce Racial and Ethnic Health Disparities Implementation Progress Report. Washington, DC: Office of the Assistant Secretary for Planning and Evaluation, 2015.

6. Viner RM, Ozer EM, Denny S, et al. Adolescence and the social determinants of health. Lancet. 2012;379:1641-1652.

7. Dunn EC, Milliren $C E$, Evans $C R$, et al. Disentangling the relative influence of schools and neighborhoods on adolescents' risk for depressive symptoms. Am J Public Health. 2015;105:732-740. 
8. Hatzenbuehler ML, Jun HJ, Corliss HL, et al. Structural stigma and sexual orientation disparities in adolescent drug use. Addict Behav. 2015;46: 14-18.

9. Maness SB, Buhi ER, Daley EM, et al. Social determinants of health and adolescent pregnancy: an analysis from the national longitudinal study of adolescent to adult health. J Adolesc Health. 2016;6:636-643.

10. Plourde KF, Fischer S, Cunningham J, et al. Improving the paradigm of approaches to adolescent sexual and reproductive health. Reprod Health. 2016;13:72.

11. Heron J, Low N, Lewis $\mathrm{G}$, et al. Social factors associated with readiness for sexual activity in adolescents: a population-based cohort study. Arch Sex Behav. 2015;44:669.

12. Li K, Liu D, Haynie D, et al. Individual, social, and environmental influences on the transitions in physical activity among emerging adults. BMC Public Health. 2016;16:682.

13. Mathur MR, Tsakos G, Parmar P, et al. Socioeconomic inequalities and determinants of oral hygiene status among Urban Indian adolescents. Community Dent Oral Epidemiol. 2016;44:248-254.

14. Centers for Disease Control and Prevention. Social Determinants of Health: Know What Affects Health. 2016. Available at www.cdc.gov/ socialdeterminants/cdcprograms/index.htm Accessed March 1, 2017.

15. U.S. Department of Health \& Human Services. Surgeon General: Nationa Prevention Strategy. Available at www.surgeongeneral.gov/priorities/ prevention/strategy Accessed March 1, 2017.

16. National Partnership for Action to End Health Disparities. U.S. Office of Minority Health. Available at https://minorityhealth.hhs.gov/npa Accessed March 1, 2017.

17. U.S. Department of Health and Human Services. Healthy Tomorrows. Available at https://mchb.hrsa.gov/training/healthy-tomorrows.asp Accessed March 3, 2017.

18. Robert Wood Johnson Foundation. RWJF Culture of Health Prize. Available at www.rwjf.org/en/library/features/culture-of-health-prize.html Accessed March 1, 2017.

19. March E, Ettinger de Cuba S, Cook JT, et al. Behind Closed Doors: The Hidden Health Impact of Being Behind on Rent. Boston, MA: Children's Health Watch, 2011.

20. Tebb KP, Rodriguez F, Pollack LM, et al. Assessing the effectiveness of a patient-centered computer-based clinic intervention, Health-E You/Salud $\mathrm{iTu}$, to reduce health disparities in unintended pregnancies among
Hispanic adolescents: study protocol for a cluster randomised control trial. BMJ Open. 2018;8:e018201.

21. American Academy of Pediatrics. American Academy of Pediatrics Recommends Pediatricians Screen for Poverty at Check-ups and Help Eliminate its Toxic Health Effects. 2016. Available at: www.aap.org/ en-us/about-the-aap/aap-press-room/pages/american-academyof-pediatrics-recommends-pediatricians-screen-for-poverty-atcheck-ups-and-help-eliminate-its-toxic-health.aspx Accessed March 1, 2017.

22. Devia C, Baker EA, Sanchez-Youngman S, et al. Advancing system and policy changes for social and racial justice: comparing a rural and urban community-based participatory research partnership in the U.S. Int J Equity Health 2017;16:17.

23. Golub M, Charlopp M, Groisman-Perelstein AE. Got low-fat milk? How a community-based coalition changed school milk policy in New York City. Fam Community Health 2010;34:S44-S53.

24. Robert Wood Johnson Foundation. The Bronx, NY: 2015 Culture of Health Prize Winner. 2015. Available at www.rwjf.org/en/library/ articles-and-news/2015/10/coh-prize-bronx-ny.html Accessed March 1, 2017.

Cite this article as: Tebb KP, Pica G, Twietmeyer L, Diaz A, Brindis CD (2018) Innovative approaches to address social determinants of health among adolescents and young adults, Health Equity 2:1, 321-328, DOI: 10.1089/heq.2018.0011

Abbreviations Used
$\mathrm{AYA}=$ adolescents and young adult
$\mathrm{LGBTQ}=$ lesbian, gay, bisexual, transgender, queer/questioning
$\mathrm{MSAHC}=$ Mount Sinai Adolescent Health Center
$\mathrm{NYCTC}=$ New York City Teen Center
$\mathrm{SCIP}=$ Spartanburg Community Indicators Projects
$\mathrm{SDOH}=$ social determinants of health
$\mathrm{SHCIP}=$ School-Based Health Center Improvement Project

